\title{
Effect of Status Epilepticus on Hypoxic-Ischemic Brain Damage in the Immature Rat
}

\author{
OGUZ CATALTEPE, ROBER'T C. VAN.VUCCI, DA.NIEL F. HEITJAN, AND JAVAD TOWFIGHI \\ Departments of Pediatrics (Pediatric Neurology) 1O.C.. R.C.V.J and Pathology (Neuropathology) [J.T.], \\ and Center for Biostatistics and Epidemiology [D.F.H.]. The Pennsylvania State University College of Medicine, \\ The Milton S. Hershey Medical Center. Hershey; Pennsylvania 17033
}

\begin{abstract}
Seven-day postnatal rats were subjected to unilateral common carotid artery ligation, $3 \mathrm{~h}$ after which they were subjected to hypoxia with $8 \%$ oxygen at $37^{\circ} \mathrm{C}$ for $2 \mathrm{~h}$. Thereafter, they received multiple s.c. injection(s) of bicuculline $(6 \mathrm{mg} / \mathrm{kg})$ adequate to produce behaviorally apparent siezures lasting greater than $1 \mathrm{~h}$ (status epilepticus). Repeated episodes of status epilepticus at 2,6 , and $12 \mathrm{~h}$ of recovery from hypoxia-ischemia (III) produced a mortality rate of $53 \%$. Among the survivors, there was no statistically significant difference in the extent of brain damage between convulsing and nonconvulsing $\mathrm{HI}$ controls, analyzed at $30 \mathrm{~d}$ of age. Histopathologic examination for acute lesions also indicated no difference in the severity of brain damage between dead and surviving rat pups subjected to status

supplementation $(0.1 \mathrm{~mL}$ of $50 \%$ glucose) early during status epilepticus improved survival and significantly prolonged seizure activity $(90+14 \mathrm{~min})$ compared with nonglucose treated, convulsing littermates $(47 \pm 10 \mathrm{~min} ; p-0.02)$. Glucose supplementation did not increase the extent of brain damage despite improved survival and increased duration of seizure activity. The findings indicate that even repetitive episodes of status epilepticus in immature rats previously subjected to cerebral HII do not accentuate brain damage despite a substantial mortality. Hypoglycemia contributes to death arising from status epilepticus, and both survival and seizures can be prolonged by glucose supplementation without risk of increasing the severity of any existing brain damage. (Pediatr Res 38: 251-257, 1995)
\end{abstract} epilepticus, indicating that mortality was not related to the severity of prior HI brain damage. Those immature rats that died during status epilepticus exhibited lower blood glucose concentrations $(1.75 \therefore 0.35 \mathrm{mmol} / \mathrm{L})$ compared with surviving, convulsing animals $(4.25 \pm 0.51 \mathrm{mmol} / \mathrm{L} ; p)-0.016)$. Glucose

Convulsive activity occurs in $50-70 \%$ of acutely asphyxiated newborn infants (1-3). The majority of newborn infants exhibit seizure activity within $24 \mathrm{~h}$ after birth; this activity is seen most frequently in those exhibiting moderate to severe HI encephalopathy. The occurrence of seizures in a previously asphyxiated newborn infant is believed by some investigators to be a strong discriminator between later normal and abnormal development $(4,5)$. Conversely, Finer et al. (1) found no relationship between the presence of HI seizures in the newborn period and ultimate outcome. Thus, the long-term prognosis of infants sustaining seizures in the newborn period might be dependent more on the type and severity of the underlying condition than on the seizure activity itself (6). Indeed, there are no clinical studies to date that demonstrate conclusively that seizures per se are damaging to the newborn

Received July 10, 1994; accepted March 25, 1995

Correspondence: Robert $C$ Vannucci. MD Department of Pediatrics (Pediatric Veurology), The Milton S. Hershey Medical Center, P.O. Box 850, Hershey, PA $17(1033$.

Supported by Grant P(11 HD 3070)4 from the National Institute of Child Health and Human Development.

\author{
Abbreviations \\ HI, hypoxia-ischemia \\ FAM, formaldehyde:acetic acid:methanol (1:1:8)
}

brain whether or not that brain has been previously damaged by HI.

Inasmuch as clinical investigations have not answered the critical question of the brain damaging potential of neonatal seizures, experimental animal studies are required to clarify the issue. Prolonged seizures or status epilepticus lead to brain damage in adult animals, with morphologic alterations in selectively vulnerable structures; especially the cerebral cortex, hippocampus, and substantia nigra (7-10). On the other hand, both published and unpublished experimental studies in immature animals of most, although not all, species have failed to demonstrate that even prolonged seizures (status epilepticus) lead to overt brain injury (11-14) (see "Discussion").

The present investigation was designed to investigate chemically induced seizures in immature rats previously subjected to cerebral III to determine whether or not either a single, prolonged seizure or repetitive seizures (status epilepticus) lead to permanent brain damage or accentuate the neuronal injury caused by the prior HI insult in these animals. We used an established model of perinatal HI brain damage, developed in 
our laboratory over 10 y ago (15). We also ascertained the contribution of hypoglycemia to mortality during status epilepticus and the extent to which glucose supplementation improves survival but also prolongs the convulsive activity.

\section{METHODS}

Dated, pregnant Sprague-Dawley rats were purchased from a commercial breeder (Charles River Laboratories, Wilmington, MA) and housed in individual cages. Offspring, delivered vaginally, were reared with their dams until time of initial experimentation at $7 \mathrm{~d}$ of postnatal age.

\section{Induction of Cerebral HI}

Cerebral HI was induced in 7-d postnatal rats by a previously described technique (15). Rat pups underwent right common carotid artery ligation under light halothane anesthesia. Upon recovery from anesthesia, the animals were returned to their dams for $3 \mathrm{~h}$. Thereafter, they were placed in $500-\mathrm{mL}$ airtight jars partially submerged in a $37^{\circ} \mathrm{C}$ waterbath to maintain a constant thermal environment. A gas mixture of $8 \%$ oxygen and $92 \%$ nitrogen was delivered into the jars via inlet and outlet portals. The rat pups were exposed to this gas mixture for $2 \mathrm{~h}$, after which they were allowed to recover for $15 \mathrm{~min}$ in open jars in the waterbath. Thereafter, the animals were returned to their dams until such time that they were injected with bicuculline. The combination of unilateral carotid artery occlusion and systemic hypoxia with $8 \%$ oxygen is known to produce damage in the form of selective neuronal necrosis or infarction of the cerebral hemisphere ipsilateral to the arterial ligation $(15,16)$.

\section{Induction and Observation of Seizures}

Bicuculline (Sigma Chemical Co., St. Louis, MO), a convulsant drug which blocks the postsynaptic inhibitory action of $\gamma$-aminobutyric acid, was dissolved in $0.1 \mathrm{~N} \mathrm{HCl}$ and refrigerated until the day of the experiment. Immediately before its administration, a portion was neutralized with $0.1 \mathrm{~N} \mathrm{NaHCO}_{3}$. Thereafter, the bicuculline was injected s.c. into rat pups recovering from cerebral $\mathrm{HI}$ in a dosage of $6 \mathrm{mg} / \mathrm{kg}$ of body weight; a dosage adequate to produce behaviorally apparent seizures lasting more than $1 \mathrm{~h}(17)$. In a preliminary study, we ascertained that a single episode of status epilepticus at $24 \mathrm{~h}$ of recovery from HI was associated with a low mortality (15\%), and neuropathologic analysis of the survivors at $30 \mathrm{~d}$ of postnatal age showed no accentuation of $\mathrm{HI}$ brain damage compared with nonconvulsing HI controls. Accordingly, in the present investigation, $7-d$ postnatal rats received multiple in jections at 2, 6, and $12 \mathrm{~h}$ of recovery from HI. Animals that were used to determine blood glucose concentrations during seizures received the same dose of bicuculline at 2, 6 , and 12 h of recovery. After the injections, the animals' behaviors were observed for $2 \mathrm{~h}$. The presence or absence of seizures, time of onset, duration, and character of the seizure were recorded. Nine additional $7-d$ postnatal rats received an injection of bicuculline, which was repeated 4 and $10 \mathrm{~h}$ later; these animals were not subjected to prior HI.

\section{Neuropathologic Analysis}

Experimental groups. Rat pups received bicuculline in three doses at 2,6 , and $12 \mathrm{~h}$ post-HI. Control animals were $\mathrm{HI}$ rat pups that received $1.0 \mathrm{~N}$ saline in a volume equal to that of bicuculline. The surviving animals were reared with their dams until $30 \mathrm{~d}$ of postnatal age, when they were killed and underwent neuropathologic analysis (see below). In a second group, rat pups received bicuculline at 2, 6, and $12 \mathrm{~h}$ after HI. Controls were $\mathrm{HI}$ animals that were not given bicuculline. In this group, each HI animal that died during the course of the convulsive activity was paired with a convulsing $\mathrm{HI}$ animal that remained alive and also with a nonconvulsing, $\mathrm{HI}$ animal. As soon as an HI animal died during the seizure, their selected littermates were decapitated, and their brains were prepared for evaluation of acute neuropathologic alterations. A third group of animals were HI rat pups that were given bicuculline at 2, 6, and $12 \mathrm{~h}$ of recovery as well as $0.1 \mathrm{~mL}$ of $50 \%$ glucose s.c. $15 \mathrm{~min}$ after the onset of the seizure activity. In this group, control animals consisted of HI, nonconvulsing animals that received $0.1 \mathrm{~mL}$ of $50 \%$ glucose. Surviving animals were reared with their dams until $30 \mathrm{~d}$ of postnatal age, when they were killed for neuropathologic analysis.

Neuropathologic methods. All rat pups surviving until 30 $\mathrm{d}$ of postnatal age were killed under deep pentobarbital anesthesia (45 mg/kg i.p.), and their brains were immediately removed from the skulls and immersed in FAM. Evaluation of the presence and extent of chronic gross morphologic and microscopic alterations was performed by two investigators, each blinded to group assignment. For gross examination, the type and extent of changes such as atrophy and cavitation were noted, as previously described $(18,19)$. The severity of damage within each brain was grossly scored as follows. Grade $0=$ normal; grade $1=$ mild brain atrophy; grade $2=$ moderate brain atrophy; grade $3=$ atrophy and cystic cavitation $<3 \mathrm{~mm}$; grade $4=$ atrophy and cystic cavitation $>3 \mathrm{~mm}$. Mild atrophy included those brains in which the transverse diameter of the ipsilateral cerebral hemisphere at the posterior (infundibular) level was up to $25 \%$ less than that of the contralateral hemisphere. Moderate atrophy included those brains in which the transverse diameter of the ipsilateral hemisphere at the posterior level was $25-50 \%$ less than that of the contralateral hemisphere but short of cystic cavitation.

For microscopic evaluation of chronic lesions in groups of rats, two hematoxylin and eosin-stained coronal sections, one at the level of the body of the anterior commissure (anterior level) and the other at the level of the infundibulum (posterior level), were scored histologically (16). Each of the involved regions was assigned a score of one, and an additional score of one was given to those regions exhibiting cystic infarction. The regions used for scoring were: anterior cortex, posterior cortex, CA1, combined CA2 and CA3, CA4, fascia dentata, amygdaloid nucleus, anterior striatum, posterior striatum, globus pallidus, and thalamus. The total sum of these scores represented the brain damage score.

For evaluation of acute lesions ( $<24 \mathrm{~h}$ post-insult), rat pups were killed under pentobarbital anesthesia, decapitated, and their 
brains with intact skulls immersed in FAM. Four to $24 \mathrm{~h}$ later, the calvarium of each brain was carefully removed, and the brain with intact skull was fixed for an additional week in FAM fixative. Then, the brain was removed and two $2-\mathrm{mm}$ thick coronal tissue blocks, one containing the anterior commissure and the other containing the infundibular region, were cut and processed for paraffin embedding. After step sectioning and hematoxylin and eosin staining, two appropriate sections of each brain were selected for semiquantitative scoring of damage. One of the sections that cuts through the mid-portion of the body of the anterior commissure included the anterior portions of the cerebral cortex and striatum (anterior level). The other section through the midportion of the median eminence (posterior level) included cerebral cortex, dorsal hippocampus, thalamus, and amygdaloid nucleus (Fig. 1). Evidence of irreversible neuronal damage included clearing or eosinophilia of perikaryon and nuclear changes, such as pyknosis and karyorrhexis. The degree of damage of each structure and its various subregions were graded as shown in Table 1.

The histologic evaluation of the damaged brains was made under a $20 \times$ objective in a microscope with a modified stage that facilitated movement of the slide in any desired direction in the horizontal plane. Evaluation of each structure will be described separately. In the cerebral cortex, both anterior and posterior cortex were divided into six segments, consisting of medial, dorsal superior, dorsal inferior, lateral superior, lateral inferior, and entorhinal cortex (Fig. 1). The total sum of grades of cortical segments represented the histologic score of the cortex. In hippocampus, due to its large size and regional variation in vulnerability, multiple determinations were made. The dorsal hippocampus was divided into the following regions: subiculum, medial CA1, lateral CA1, combined CA2 and lateral CA3, medial CA3, CA4, and fascia dentata. In each of the above regions, the damaged neurons were evaluated and graded. The total sum of these grades represented the histologic score of hippocampus. In thalamus, striatum, and amygdaloid nucleus, due to the different vulnerability of their various regions, lateral and medial parts were graded separately by



Figure 1. Diagrams of anterior (right) and posterior (left) level sections of cerebral hemisphere of the immature rat. Structures are subdivided for histologic scoring of damage. $A$ through $F$ and $A^{\prime}$ through $F^{\prime}$, cortical subdivisions: $S$, subiculum; $D G$, dentate gyrus; $M C A l$ and $L C A 1$, medial and lateral CA1; $L C A 3$ and $M C A 3$, lateral and medial $C A 3 ; M C P$ and $L C P$, medial and lateral caudoputamen; $M T^{\top}$ and $L T$, medial and lateral thalamus; $M A$ and $L A$, medial and lateral amygdaloid nucleus; $a c$, anterior commissure.
Table 1. Grading of degree of brain damage

\begin{tabular}{cl}
\hline Grade & Gray matter \\
\hline 0 & Normal \\
1 & Few neurons damaged $(1-5 \%)$ \\
2 & Several neurons damaged $(6-25 \%)$ \\
3 & Moderate number of neurons damaged $(26-50 \%)$ \\
4 & Greater than one-half of neurons damaged $(51-75 \%)$ \\
5 & Majority or all neurons damaged including infarction $(>75 \%)$ \\
\hline
\end{tabular}

the use of an ocular grid in the microscope, and the total sum of grades for each structure represented its histologic score. The histologic score of damage for each brain was represented by the total sum of scores of regions of the various structures.

\section{Blood Glucose Concentrations}

Blood glucose levels were determined in $24 \mathrm{HI}$ rat pups during seizure activity after multiple injections of bicuculline $(2,6$, and $12 \mathrm{~h}$ after $\mathrm{HI})$. Each rat pup that died during a seizure was randomly combined with another convulsing HI rat pup that remained alive as well as with a nonconvulsing $\mathrm{HI}$ rat pup. When a HI rat pup died during the seizure activity, its selected littermates were decapitated, and blood samples of all animals were collected from the severed neck vessels into capillary tubes for analysis of plasma glucose on a micro-glucose analyzer (Beckman Glucostat, Fullerton, CA). Plasma glucose concentrations also were determined in non-HI, nonconvulsing rat pups that served as controls. The blood glucose profile of $\mathrm{HI}$ animals that received bicuculline also was determined during the course of status epilepticus. At specific intervals $(0,15,30$, 45,60 , and $90 \mathrm{~min}$ ) after the onset of seizures, the animals were decapitated, and plasma glucose levels were determined.

In another study group, $\mathrm{HI}$ rat pups received $0.1 \mathrm{~mL}$ of $50 \%$ glucose s.c. $15 \mathrm{~min}$ after the onset of seizure activity to determine the substrate's effect on seizure duration and mortality. HI rat pups that received glucose were compared with HI rat pups that did not receive glucose during the seizure. All animals were decapitated after the seizure, and blood glucose levels were measured.

\section{Statistical Analyses}

Minitab statistical software was used for data transformation and statistical analysis. Statistical comparisons were performed using analysis of variance, two sample $t$, paired $t$, and Mann Whitney $U$ tests. $p<0.05$ was selected as the criterion of significance.

\section{Institutional Approval}

The experiments described here were reviewed by the Animal Care and Use Committee of The Milton S. Hershey Medical Center, The Pennsylvania State University, and approved on October 1, 1992.

\section{RESULTS}

Behaviorally apparent seizures. HI animals which received bicuculline exhibited a variety of seizures ranging from myoclonic jerks to generalized status epilepticus (see also Ref. 17). 
The rat pups initially became immobile, and a few minutes later they became aggitated and started to circle. Circling gradually increased and was followed by running, squealing, and rolling activity with increased tonus of the entire body. The tonic phase was associated with apnea and urinary incontinence. The tonic posture and apneic episodes lasted for 3-5 min. Thereafter, tonic-clonic seizures commenced with associated swimming-like movements which continued until interrupted by another tonic or clonic fit. These behaviorally apparent seizures previously have been shown to be associated with paroxysmal discharges recorded electrically and ranging from repetitive spike activity to spike/slow wave discharges (17).

Chronic neuropathologic alterations. In the initial experiment, 47 immature rats received bicuculline at 2,6 , and $12 \mathrm{~h}$ of recovery from HI. In this group, a single animal died after the first dose. Second dose mortality was $41 \%$, whereas third dose mortality was $19 \%$, giving an overall mortality of $53 \%$. Three animals also died during the extended recovery phase. Gross inspection of the brains of the 20 surviving animals at $30 \mathrm{~d}$ of postnatal age showed no difference in the extent of damage between those animals subjected to multiple, prolonged seizures and 20 control HI animals $(p>0.05)$ (Fig. 2). Histologic examination and scoring of the severity of damage in the same brains also revealed no difference in the extent of regional or global injury between those animals subjected to multiple, prolonged seizures and control HI animals. The mean brain damage score of the convulsing animals was $4.9 \pm 1.1$ (SEM) compared with a mean damage score of $5.1 \pm 1.4$ in the nonconsulving control littermates $(p>0.05)$. To ascertain whether or not repetitive status epilepticus per se caused brain damage, nine 7-d postnatal rats received an injection of bicuculline, after which injections were repeated 4 and $10 \mathrm{~h}$ later to mimic the situation after HI. Four of the nine rat pups previously underwent unilateral common carotid artery ligation, but none of the animals was exposed to systemic hypoxia. All

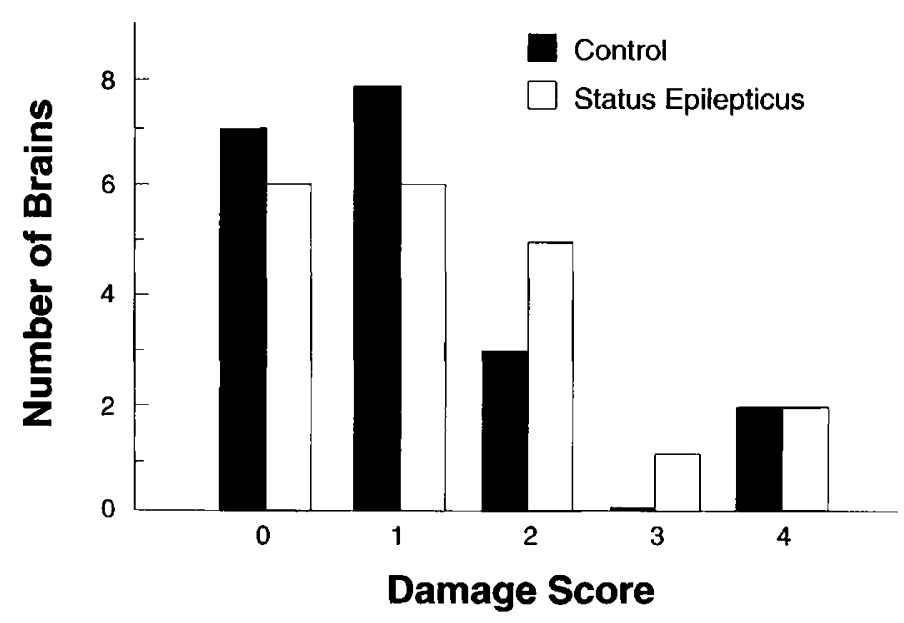

Figure 2. Incidence and severity of gross brain damage in immature rats subjected to HI followed by multiple episodes of status epilepticus. Seven-day postnatal rats previously subjected to $\mathrm{HI}$ received injections of bicuculline at 2 , 6 , and $12 \mathrm{~h}$ of recovery; littermate controls received $1.0 \mathrm{~N}$ saline. Bars represent numbers of animals exhibiting brain damage, ranging from no damage (0) to cystic infarction (4) (see "Methods"). animals survived the repetitive seizures, and neuropathologic analysis at $30 \mathrm{~d}$ of postnatal age revealed no brain damage in all of the animals.

Acute histologic alterations. To ascertain acute histologic alterations which occurred during the course of multiple seizures in immature rats, 24 7-d postnatal rats underwent HI, after which they received doses of bicuculline at 2, 6, and 12 $h$ of recovery. Those rat pups that died during the course of the seizure activity were immediately decapitated, and their brains were examined histologically. For every dead animal, an alive convulsing rat pup was killed and its brain also examined histologically. Control littermates consisted of nonconvulsing, HI animals that also were killed for neuropathologic evaluation. All brains were processed for quantitative histologic analysis as described in "Methods." The vulnerable structures of the cerebral hemisphere ipsilateral to the carotid artery occlusion then were compared among the three groups. Of the convulsing animals previously subjected to $\mathrm{HI}$, there was no statistically significant difference in the extent of brain damage between the dead and surviving animals $(p>0.05)$ (Fig. 3). There was also no statistically significant difference in the severity of brain damage between the nonconvulsing, $\mathrm{HI}$ animals and either the dead or surviving convulsing animals $(p>$ $0.05)$. Injured structures included the anterior and posterior cerebral cortex, hippocampus, striatum, thalamus, and amygdaloid nucleus. An incidential finding of the experiment was

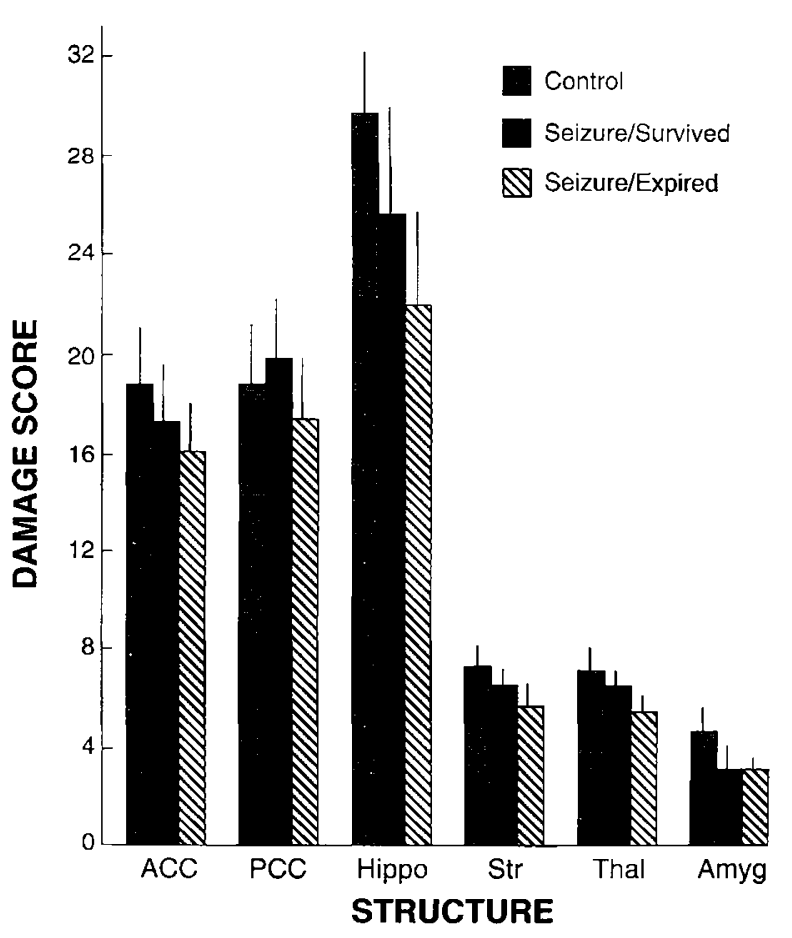

Figure 3. Severity of damage to selected brain structures of immature rats subjected to status epilepticus after HI. Bars represent mean damage scores of either surviving or expired convulsing rat pups; controls consisted of nonconvulsing, HI littermates. Vertical lines denote \pm 1 SEM. Damage scores of each structure were determined histologically as described in "Methods." Abbreviations: $A C C$, anterior cerebral cortex; $P C C$, posterior cerebral cortex; Hippo, hippocampus; Str, striatum; Thal, thalamus; Amyg, amygdaloid nucleus. 
the presence of damage within the cortex of the cerebral hemisphere contralateral to the carotid artery occlusion. Contralateral damage was seen in $23 \%$ of the animals which expired during course of the seizure, and the incidence of this damage was $25 \%$ in those animals surviving the status epilepticus $(p>0.05)$. Contralateral cerebral hemispheric damage also was seen in $2 / 12(17 \%)$ immature rats subjected to $\mathrm{HI}$ alone, not statistically different from the incidence of contralateral damage in the convulsing animals $(p>0.05)$.

Blood glucose concentrations. To determine whether or not hypoglycemia contributed to mortality during status epilepticus, plasma glucose concentrations were determined in rat pups that died during the course of the seizure activity, and the results were compared with surviving animals and with nonconvulsing HI controls. Mean blood glucose in animals dying during status epilepticus was $1.75 \pm 0.35 \mathrm{mmol} / \mathrm{L}$, significantly lower than in surviving, convulsing animals (4.25 \pm $0.51 \mathrm{mmol} / \mathrm{L} ; p=0.016$ ). The mean blood glucose concentration of nonconvulsing $\mathrm{HI}$ littermates was $6.77 \pm 0.28 \mathrm{mmol} / \mathrm{L}$, significantly higher than those of the convulsing animals $(p<$ 0.001). The time course of the changes in blood glucose concentration during the course of status epilepticus is shown in Figure 4.

Because hypoglycemía contributed to mortality during status epilepticus, an additional experiment was performed whereby convulsing $\mathrm{HI}$ animals received $0.1 \mathrm{~mL}$ of $50 \%$ glucose $15 \mathrm{~min}$ after the onset of status epilepticus; control convulsing littermates received $1.0 \mathrm{~N}$ saline. Seizure duration was significantly longer in the glucose-treated, convulsing animals $(90 \pm 14 \mathrm{~min})$ than in the nonglucose treated, convulsing littermates $(47 \pm 10 \mathrm{~min} ; p=0.02)$. Indeed, some of the glucose-treated rats convulsed for up to $3 \mathrm{~h}$. The mortality rate was the same $(45 \%)$ in the two groups. An additional group of glucose-treated and nonglucose-treated rat pups received doses of bicuculline at 2,6 , and $12 \mathrm{~h}$ after HI. Survivors were reared with their dams until $30 \mathrm{~d}$ of postnatal age, after which their brains were analyzed for the presence and extent of brain damage. As in the previous investigations (see above), there was no statistically significant difference between the

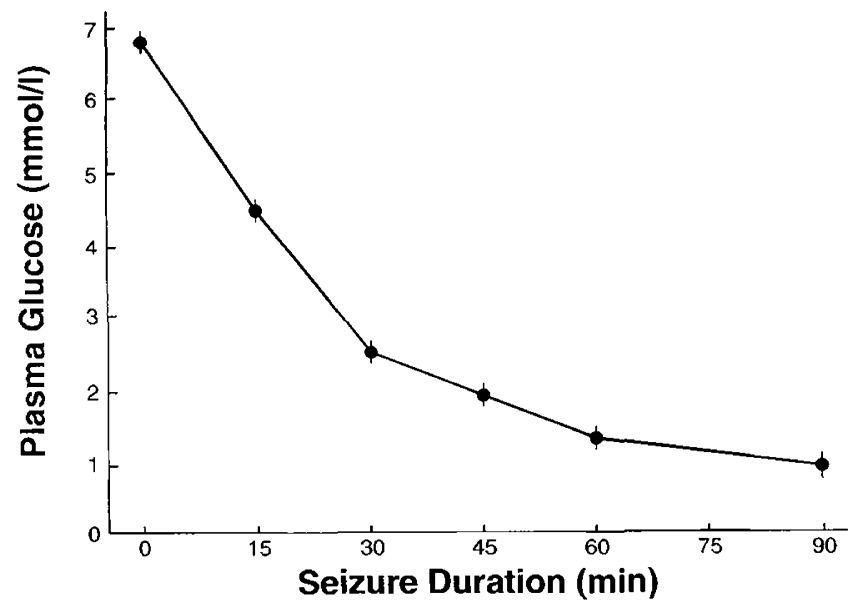

Figure 4. Plasma glucose concentrations during the course of status epilepticus in immature rats. Circles represent means of three to six animals; vertical lines denote \pm 1 SEM. extent of brain damage in the glucose-treated and nonglucosetreated animals undergoing status epilepticus after $\mathrm{HI}(p>$ 0.05) (Fig. 5).

\section{DISCUSSION}

In adult rats, status epilepticus readily leads to brain damage $(8,10,20)$. In contrast, immature rats appear resistant to the brain damaging effect of status epilepticus. Several investigators have attempted to produce epileptic brain damage in developing rats by the use of a variety of convulsant drugs (bicuculline, fluorothyl, kainic acid) as well as sequential electroshock $(11-13,20-22)$. Collectively, the results of these studies indicate that, despite status epilepticus of $90 \mathrm{~min}$ or more, rat pups less than $20 \mathrm{~d}$ of postnatal age remain free of brain damage, whereas those which are $20 \mathrm{~d}$ and older exhibit neuronal necrosis in a distribution comparable to that of adults. The reason for the resistance of immature rats to epileptic brain damage is not yet fully clarified (see below).

Although immature rats are resistant to the brain damaging effect of status epilepticus, such is not the case for rabbits. Franck and Schwartzkroin (23) produced status epilepticus in 7-d postnatal rabbits with systemically administered kainic acid, $2 \mathrm{~d}$ after which their brains underwent histopathologic analysis. Moderate to severe damage of the subiculum, CA1 sector, and interneurons of the hippocampus, the thalamus, the cerebral cortex, and other structures was seen in all previously convulsing animals. The species difference in the sensitivity of the immature brain to status epilepticus is unexplained, especially because the anatomic and functional maturity of 7-d postnatal rats and rabbits are comparable (24). Whether or not the epileptic brain damage exhibited by immature rabbits can be accentuated by prior $\mathrm{HI}$ is yet to be determined.

The experiments described in the present investigation were designed to ascertain whether or not one or more episodes of

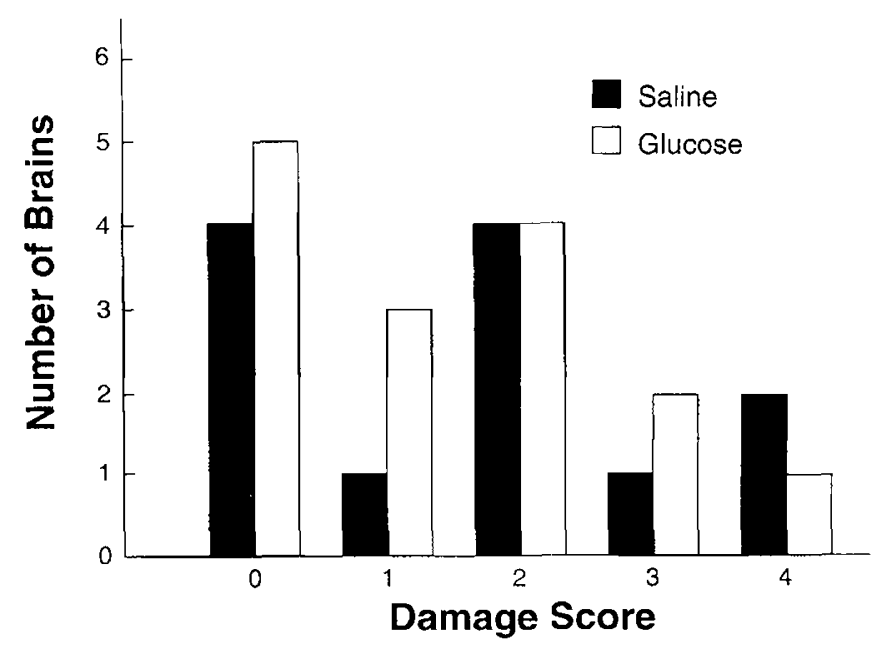

Figure 5. Incidence and severity of brain damage in immature rats subjected to HI followed by multiple episodes of status epilepticus with glucose supplementation. Seven-day postnatal rats were subjected to $\mathrm{HI}$ after which they received an injection of bicuculline at 2,6 , and $12 \mathrm{~h}$ of recovery. Fifteen minutes after the onset of seizure activity, rat pups received $0.1 \mathrm{~mL}$ of $50 \%$ glucose. Controls consisted of $\mathrm{HI}$, nonconvulsing littermates that also received glucose. Bars represent numbers of animals exhibiting brain damage, ranging from no damage $(0)$ to cystic infarction (4) (see "Methods"). 
status epilepticus in the immature rat causes permanent brain damage or accentuates tissue injury produced by immediately preceding cerebral HI. The results allow for several conclusions. First, status epilepticus, even when associated with a substantial mortality, does not cause overt histopathologic damage in immature rat brain. Second, even repetitive status epilepticus superimposed on brain damage produced by prior $\mathrm{HI}$ does not accentuate tissue necrosis, whether the antecedent damage is mild, moderate, or severe. Third, hypoglycemia contributes to death arising from status epilepticus. Fourth, both survival and seizures can be prolonged by glucose supplementation without risk of increasing the severity of any existing brain damage.

The present experiments extend a previous finding by Wasterlain and Duffy (25) that hypoglycemia contributes to mortality in immature rats subjected to prolonged seizure activity and that survival during status epilepticus is prolonged by glucose supplementation. The present study shows that glucose treatment also prolongs the seizure activity but without any increase in brain damage caused by prior HI. The origin of the hypoglycemia undoubtedly is related to increased utilization of glucose by peripheral tissues, especially skeletal muscle, which participate in the convulsive activity. Adult rats are less prone to hypoglycemia during status epilepticus (25); but, as in immature rats, glucose treatment perpetuates the seizure activity (26), presumably by replenishing previously diminished brain carbohydrate stores (27, 28 ). By prolonging the status epilepticus, epileptic brain damage is increased, possibly through the mechanism of enhanced tissue lactic acid formation (29).

The mechanism whereby epileptic brain damage occurs in adult but not immature rats is unresolved. At least in the immature rat, a cellular energy failure does not occur during status epilepticus, because the energy reserves, ATP and phosphocreatine, are well preserved during the course of the insult $(25,30)$. In this regard, cerebral energy utilization in the 7-d postnatal rat is $1: 10$ that of the adult (31). Assuming that up to $2 \mathrm{~h}$ of status epilepticus is required to produce permanent brain damage in adult rats $(8,9)$, it is possible that up to $20 \mathrm{~h}$ of status epilepticus would be required to produce brain damage in the immature rat. Specifically, the lower the cerebral metabolic rate produced by immaturity, the longer the required insult to produce brain injury (32).

Epileptic brain damage in adult animals results from or at least is initiated by an excessive stimulation of excitatory amino acid cell membrane receptors and its associated intracellular calcium (and sodium) overload of selectively vulnerable neurons (for reviews, see Refs. 26 and 33). Possibly, epileptic excitotoxicity does not occur in the immature rat, owing to a blunted release of excitatory (glutamate, aspartate) neurotransmitters into the synaptic cleft after depolarization (34) or to a more favorable balance between the major excitatory and inhibitory (glycine, $\gamma$-aminobutyrate) neurotransmitters. In the latter regard, we recently have measured cerebrospinal fluid concentrations of glutamate and $\gamma$-aminobutyrate as a reflection of extracellular concentrations during and immediately after status epilepticus in the immature rat and have found that the percentage increases in the level of the inhibitory neurotransmitter exceed that of the excitatory amino acid (our unpublished data).

In summary, the findings of the present investigation indicate that even repetitive episodes of status epilepticus in immature rats previously brain damaged by $\mathrm{HI}$ do not accentuate brain damage despite a substantial mortality. Hypoglycemia contributes to death arising from status epilepticus, and both survival and seizures can be prolonged by glucose supplementation without apparent risk of increasing the severity of any existing brain injury. Given the species difference in the sensitivity of the immature brain to epileptic brain damage with or without prior HI, further research is warranted to clarify the issue of the potential deleterious effect of prolonged seizures on the developing brain.

\section{REFERENCES}

1. Finer NN, Robertson CM, Richards RT, Pinnell LE, Petters KL 1981 Hypoxic ischemic encephalopathy in term neonates: Perinatal factors and outcome. J Pediatr 98:112-117

2. Mizrahi EM, Kcllaway P 1987 Characterization and classification of neonatal seizures. Neurology 37:1837-1844

3. Volpe JJ 1989 Nconatal seizures. Current concepts and revised classification. Pediatrics $84: 422-428$

4. Nelson KB, Broman RL 1977 Perinatal risk factors in children with serious motor and mental handicaps. Ann Neurol 2:371-377

5. Mulligan JC, Painter MJ, O'Donoughue PA, MacDonald HM, Allcn AC, Taylor PM 1980 Nconatal asphyxia. II. Neonatal mortality and long-term sequelae. J Pcdiatr 96:903-907

6. Volpe JJ 1986 Neurology of the Newborn. WB Saunders, Philadelphia

7. Meldrum BS, Brierley JB 1973 Prolonged epileptic seizures in primates: Ischemic cell change and its relation to ictal physiological events. Arch Neurol 28:10-17

8. Soderfeldt B, Kalimo H, Olsson Y, Siesjo BK 1981 Pathogenesis of brain lesions caused by experimental epilepsy: Light and electron-microscopic changes in the rat ccrebral cortex following bicuculline-induced SE. Acta Neuropathol 54:219231

9. Nevander G, Ingvar M, Auer R, Siesjo BK 1985 Status cpilepticus in well-oxygenated rats causes neuronal nccrosis. Ann Neurol 18:281-290

10. O'Connell BK, Towfighi J, Kofkc WA, Hawkins RA 1988 Neuronal lesions in mercaptopropionic acid-induced status epilepticus. Acta Neuropathol 77:47-54

11. Wasterlain CG, Plum F 1973 Vulnerability of developing rat brain to electroconvulsive scizures. Arch Neurol 29:38-45

12. Albala BJ, Moshe SL, Okada R 1984 Kainic acid-induced seizures: A developmental study. Dev Brain Res 13:139-148

13. Nitecka L, Tremblay E, Charaton G, Boulliout JP, Berger ML, Ben-Ari Y 1984 Maturation of kainic acid seizure-brain damage syndrome in the rat: Histopatholog ical scquelae. Neuroscience 13:1073-1094

14. Fujikawa DG, Soderfeldt B, Wasterlain CG 1992 Neuropathological changes during generalized scizures in newborn monkeys. Epilepsy Res 12:243-251

15. Rice JE, Vannucci RC, Brierley JB 1981 The influcnce of immaturity on hypoxicischemic brain damage in the rat. Ann Neurol 9:131-141

16. Towfighi J, Yager JY, Housman C, Vannucci RC 1991 Ncuropathology of remote hypoxic-ischemic damage in the immature rat. Acta Neuropathol 81:578-587

17. Cataltepc O, Barron TF, Heitjan DF, Vannucci RC, Towfighi J 1995 Effect of hypoxia-ischemia on bicuculline induced seizures in immature rats: Behavioral and clectrocortical phenomena. Epilepsia 36:396-403

18. Palmer C, Vannucci RC, Towfighi J 1990 Reduction of perinatal hypoxic-ischemic brain damage with allopurinol. Pcdiatr Res 27:332-336

19. Yager JY, Heitjan DF, Towfighi J, Vannucci RC 1992 Effect of insulin-induced and fasting hypoglycemia on perinatal hypoxic-ischemic brain damagc. Pediatr Res $31: 138-142$

20. Cuvalheiro EA, Silva DF, Turski WA, Caldcrazzo-Filho LS, Bortolotto ZA, Turski L 1987 The susceptibility of rats to pilocarpine-induced seizures is age-dependent. Dev Brain Res 37:43-58

21. Sperber EF, Haas KZ, Stanton PK, Moshe SL 1991 Resistance of the immature hippocampus to seizure-induced synaptic reorganization. Dev Brain Res $60: 88-93$

22. Stafstrom CE, Thompson JL, Holmes GL 1992 Kainic acid seizures in the developing brain: Status epilepticus and spontaneous recurrent scizures. Dev Brain Res 65:227-236 23. Franck JE, Schwartzkroin PA 1984 Immaturc rat hippocampus is damaged by systemic but not intraventricular kainic acid. Dev Brain Res 13:219-227

24. Himwich WA 1973 Problems in interpreting neurochemical changes occurring in developing and aging animals. Prog Brain Res 40:13-23

25. Wasterlain CG, Duffy T 1976 Status epilepticus in immature rats: Protective effects of glucose on survival and brain devclopment. Arch Neurol 33:821-827

26. Siesjo BK, Ingvar $M$, Wieloch T 1986 Cellular and molecular events underlying epileptic brain damagc. Ann NY Acad Sci 462:208-223 
27. Blennow G, Folbergrova J, Nilsson B, Siesjo BK 1979 Effects of bicuculline-induced seizures on cerebral metabolism and circulation of rats rendered hypoglycemic by starvation. Ann Neurol 5:139-151

28. Folbergrova J, Ingvar M, Siesjo BK 1981 Metabolic changes in cerebral cortex hippocampus and cerebellum during sustained bicuculline-induced seizures. $J$ Neurochem 37:1228-1238

29. Ingvar M, Folbergrova J, Siesjo BK 1987 Metabolic alterations underlying the development of hypermetabolic necrosis in the substantia nigra in status cpilcpticus. J Cereb Blood Flow Metab 7:103-108

30. Sacktor B, Wilson JE, Tiekert CG 1966 Regulation of glycolysis in brain, in situ, during convulsions. J Biol Chem 241:5071-5075
31. Duffy TE, Kohle SJ, Vannucci RC 1975 Carbohydrate and energy metabolism in perinatal rat brain: Relation to survival in anoxia. J Neurochem 24:271-276

32. Vannucci RC 1982 Vulnerability of the immature brain to hypoxia-ischemia. In: Environmental Effects of Maturation. Cold Spring Harbor Symposium, Banbury Report II, pp 2691-2798

33. Mcldrum BS 1994 The role of glutamate in epilepsy and other CNS disorders. Neurology 44(suppl 8):S14-S23

34. Collard KJ, Edwards R, Liu Y 1993 Changes in synaptosomal glutamate release during postnatal development in the rat hippocampus and cortex. Dev Brain Res $71: 37-43$ 